appointing, and it seems unlikely that streptokinase will play an important part in the treatment of such patients (Hirsh et al., 1968). Finally, while we obtained rapid resolution of minor recent emboli in two patients it must remain arguable whether any treatment, carrying with it the risk of haemorrhagic complications, is justifiable in such patients.

\section{REFERENCES}

Allison, P. R., Dunnill, M. S., and Marshall, R. (1960). Thorax, 15, 273. Barritt, D. W., and Jordan, S. C. (1960). Lancet, 1, 1309.

British Medical fournal, 1968, 4, 133.

Browse, N. L., and James, D. C. O. (1964). Lancet, 2, 1039.

Cotton, L. T., Flute, P. T., and Tsapogas, M. J. C. (1962). Lancet, 2, 1081
Dickie, K., de Groot, W., Cooley, R., Guest, M. M., and Bond, T. (1967) Tex. Rep. Biol. Med., 25, 613 .

Fred, H. L., Axelrad, M. A., Lewis, J. M., and Alexander, J. K. (1966). 7. Amer. med. Ass., 196, 1137.

Goodwin, J. F., Harrison, C. V., and Wilcken, D. E. L. (1963). Brit. Med. F., 1, 701.

Gorham, L. W. (1961). Arch. intern. Med., 108, 8.

Hirsh, J., Hale, G. S., McDonald, I. G., McCarthy, R. A., and Cade, J. F. (1967). Lancet, 2, 593.

Hirsh, J., Hale, G. S., McDonald, I. G., McCarthy, R. A., and Pitt, A. (1968). Brit. med. F., 4, 729.

Lancet, 1966, 2, 1169.

Scholander, P. F. (1947). F. Biol. Chem., 167, 235.

Thomas, D. P. (1965). New Engl. 7. Med., 273, 885.

Tow, D. E., and Wagner, H. N. (1967). New Engl. F. Med., 276, 1053. Medicine, 276, 1053.

Zijlstra, W. G., and Mook, G. A. (1962). Medical Reflection Photometry, V.an Gorcum, Assen, The Netherlands.

\title{
Value of Routine Cardiac Monitoring in the Management of Acute Myocardial Infarction outside a Coronary Care Unit
}

\author{
P. J. B. HUBNER,*§ M.B., M.R.C.P. ; M. J. GOLDBERG,† M.B., DIP.MED., M.R.C.P. ; C. W. LAWSON, $\ddagger$ M.D., F.R.C.P.
}

Brit. med. F., 1969, 1, 815-817

$S^{\text {u }}$ mmary : In a coronary care unit patients and electrocardiographic monitors are under almost continuous observation by trained personnel. This paper suggests that in a general medical ward without this facility routine cardiac monitoring with E.C.G. oscilloscopes is unlikely to lower the overall mortality from acute myocardial infarction. A mortality of $25 \%$ for acute myocardial infarction was the same for a hospital without a coronary care unit where monitoring was routinely performed and for two neighbouring hospitals which did not routinely use monitoring during the period of analysis.

The need to train personnel in the recognition of E.C.G. monitor tracings and the difficulties associated with monitor alarm systems are emphasized.

\section{Introduction}

Treatment of patients in coronary care units has been shown to lower the mortality from acute myocardial infarction (Fluck et al., 1967 ; Lawrie et al., 1967 ; Lown et al., 1967 ; Restieaux et al., 1967). This paper attempts to assess the value of routine cardiac monitoring with E.C.G. oscilloscopes in a hospital ward, without the full facilities of a coronary care unit. The results of this management are compared with those from two series of patients admitted to general hospital medical wards, where monitoring was not routinely used during the period analysed. The severity of infarction was determined to discover whether the three management groups were comparable.

\section{Material and Methods}

\section{Hospitals}

Admissions for acute myocardial infarotion to three Leicester hospitals were studied. At Groby Road Hospital, which is a regional cardiac unit, both male and female patients were admitted to the same ward, consisting of cubicles for one or two patients opening on to a long corridor. All patients with myocardial infarction were monitored for the first 48 hours, or longer if necessary. There was no coronary care unit on the ward. Two to four patients, though not always with myocardial infarction, were usually being monitored at any one time. The sisters and staff nurses were acquainted with the normal electrocardiographic (E.C.G.) rhythm pattern ; they had experience at the recognition on the monitor of traces showing extrasystoles, bradycardia, heart block, and tachycardia. However, no formal course of instruction on E.C.G. arrhythmia patterns had been given to them. Arrhythmias were actively sought for by medical and nursing staff.

At the other two hospitals-the Leicester General Hospital and the Leicester Royal Infirmary-patients with acute myocardial infarction were admitted to general medical wards and were not routinely monitored. The Leicester Royal Infirmary has an intensive therapy ward which in 1966 cared for drug poisoning $(25 \%)$, trauma $(33 \%)$, postoperative patients $(13 \%)$, myocardial infarction (6\%), and other medical conditions $(23 \%)$. The small propontion of patients with myocardial infarction admitted to intensive therapy ward were either severe cases or relatively young patients, and were usually monitored. Because their number was small-that is, 20 out of 162 myocardial infarction patients-and as no significant features were found on their analysis, they have not been separated from the Leicester Royal Infirmary figures.

All cases of acute myocardial infarction admitted to these hospitals over a 13-month period were analysed. The series consists of 102 patients admitted to Groby Road Hospital from 1 May 1966 to 31 May 1967 and 147 and 162 patients admitted to the Leicester General Hospital and the Leicester Royal Infirmary respectively, from 1 December 1965 to 31 December 1966. The later period was chosen for Groby Road Hospital so that six months' experience with monitoring equipment had

\footnotetext{
* Senior House Officer.

+ Consultant Cardiologist

Consultant Physician.

Department of Cardiology, The Groby Road Hospital, Leicester.

$\checkmark$ Present address: Department of Medicine, Hammersmith Hospital, London W.12.
} 
been obtained by the staff before the period covered by the study.

It was considered important that the case notes of all patients admitted with myocardial infarction during the period of study be obtained if analysis was to be accurate. This was achieved by careful cross-checking with the hospital record offices and the ward admission books.

\section{Diagnosis of Myocardial Infarction}

The criteria used for diagnosis were a typical history and E.C.G. changes consisting of significant $Q$ waves and/or of serial S-T and T-wave changes or a left bundle-branch block pattern. The diagnosis was usually confirmed by raised serum transaminase levels and/or at necropsy. The emphasis was always to exclude a doubtful case from the series. Only patients admitted within five days of the onset of pain, or the last attack of pain, were analysed.

\section{Severity of Infarction}

The severity of infarction was assessed by the coronary prognostic index (Peel et al., 1962) with three modifications and by a simpler clinical grading of severity.

(1) Coronary Prognostic Index.-A score is recorded for six features-namely, age and sex, previous history, shock, failure, infarction pattern of E.C.G., and rhythm. The higher the score given, the more severe is the case of infarction and the poorer the prognosis.

In this study three alterations were made in the use of the index. As this was a retrospective analysis, it was frequently not possible to determine whether signs of shock on admission subsided with rest and sedation; a score of 5 was therefore given if any of the signs of shock mentioned in the index were present at the initial examination. Similarly, sinus tachycardia was scored for if it was present on admission (as opposed to scoring for persistent sinus tachycardia). Finally, a scoring for a Q-S pattern was given if any of the E.C.G.s of the hospital stay showed such a pattern. This was done because the admission E.C.G. had been mislaid from the notes of a few patients. Patients were divided by the index score into four groups: group 1, score 0-9; group 2, score 10-18; group 3, score 19-28; and group C.A., cardiac arrest on arrival.

(2) Clinical Grading.-By this grading an attempt was made to assess the severity of infarction by the initial examination of the patient alone. No account was taken of the history or the type of E.C.G. infarction pattern. With arrhythmias, only those recorded at the time of the initial examination or E.C.G. were included. Patients were divided into four grades.

Grade $A$ : No features of failure or shock, systolic B.P. $120 \mathrm{~mm}$. $\mathrm{Hg}$ or greater, no arrhythmia.

Grade $B$ : Any sign of heart failure-basal rales, raised jugular vein pressure or gallop rhythm ; or pallor or sweating ; or systolic B.P. 70 to less than $120 \mathrm{~mm}$. $\mathrm{Hg}$; or any arrhythmia, excluding ventricular fibrillation or asystole, but including sinus bradycardia and tachycardia (heart rate 60 or less, and 110 or more respectively).

Grade $C$ : Severe left ventricular failure or systolic B.P. less than $70 \mathrm{~mm} . \mathrm{Hg}$.

Grade C.A : Cardiac arrest on arrival.

\section{Other Features}

The number and mortality of patients observed to have one or more arrhythmias (a) on admission, and (b) at any time of the hospital stay, were determined. Sinus bradycardia and tachycardia (as defined above) and cardiac arrest were included as arrhythmias; sudden death was excluded, as the interest lay in observed arrhythmias. The number of deaths in the first 48 hours after admission and whether resuscitation was attempted on these patients were determined.

\section{Results}

Severity of Infarction.-Tables I and II show that by both methods of assessment the distribution of the severity of infarction cases was very similar between the hospitals. On this basis the three groups are considered comparable.

\begin{tabular}{|c|c|c|c|c|c|c|c|c|c|c|c|c|c|}
\hline \multirow{3}{*}{ Hospital } & I. $-\mathrm{Cor}$ & ronary & & & $\begin{array}{r}\text { stic I } \\
\text { Mor }\end{array}$ & $\begin{array}{l}\text { Inde } \\
\text { rtalit }\end{array}$ & & Percen & atage & Dis & tribut & tion & and \\
\hline & \multirow{2}{*}{ Total } & \multicolumn{3}{|c|}{1} & \multicolumn{3}{|c|}{2} & \multicolumn{3}{|c|}{3} & \multicolumn{3}{|c|}{ C.A. } \\
\hline & & No. & $\%$ & $\% \dagger$ & No. & $\%$ & $\% t$ & No. & $\%$ & $\% t$ & No. & $\%$ & $\% t$ \\
\hline $\begin{array}{l}\text { G.R.H. } \ldots \\
\text { L.G.H. } \\
\text { L.R.I. }\end{array}$ & $\begin{array}{l}102 \\
147 \\
162\end{array}$ & \begin{tabular}{|l|}
32 \\
53 \\
53
\end{tabular} & $\begin{array}{l}31 \\
30 \\
33\end{array}$ & $\begin{array}{l}6 \\
7 \\
6\end{array}$ & \begin{tabular}{|l|}
50 \\
72 \\
77
\end{tabular} & $\begin{array}{l}49 \\
49 \\
47\end{array}$ & $\begin{array}{l}34 \\
22 \\
27\end{array}$ & $\begin{array}{l}19 \\
29 \\
29\end{array}$ & $\begin{array}{l}19 \\
20 \\
18\end{array}$ & \begin{tabular}{|l|}
26 \\
59 \\
48
\end{tabular} & $\left|\begin{array}{l}1 \\
2 \\
3\end{array}\right|$ & \begin{tabular}{l|}
1 \\
1 \\
2
\end{tabular} & $\begin{array}{r}100 \\
100 \\
67\end{array}$ \\
\hline
\end{tabular}

In Tables I to IV: No. refers to the number of patients in the subgroup $\%$ refers to the number of patients in the subgroup, expressed as a percentage of the total number of patients admitted to that hospital as a percentage of the total number of patients within that subgroup.

TABLE II.-Clinical Grading. Percentage Distribution and Mortality

\begin{tabular}{|c|c|c|c|c|c|c|c|c|c|c|c|c|c|}
\hline \multirow{2}{*}{ Hospital } & \multirow{2}{*}{ Total } & \multicolumn{3}{|c|}{ A } & \multicolumn{3}{|c|}{ B } & \multicolumn{3}{|c|}{ C } & \multicolumn{3}{|c|}{ C.A. } \\
\hline & & | No. & $\%$ & $\%+$ & No. & $\%$ & $\% t$ & No. & $\%$ & $\% t$ & No. & $\%$ & $\% t$ \\
\hline $\begin{array}{l}\text { G.R.H. } \\
\text { L.G.H. } \\
\text { L.R.I. }\end{array}$ & $\begin{array}{l}102 \\
147 \\
162\end{array}$ & $\begin{array}{l}21 \\
28 \\
32\end{array}$ & $\begin{array}{l}20 \\
19 \\
20\end{array}$ & $\begin{array}{r}10 \\
11 \\
6\end{array}$ & $\begin{array}{r}73 \\
102 \\
113\end{array}$ & $\begin{array}{l}72 \\
70 \\
69\end{array}$ & $\begin{array}{l}25 \\
22 \\
25\end{array}$ & $\begin{array}{r}7 \\
15 \\
14\end{array}$ & $\begin{array}{r}7 \\
10 \\
9\end{array}$ & $\begin{array}{l}57 \\
73 \\
57\end{array}$ & $\begin{array}{l}1 \\
2 \\
3\end{array}$ & $\begin{array}{l}1 \\
1 \\
2\end{array}$ & $\begin{array}{r}100 \\
100 \\
67\end{array}$ \\
\hline
\end{tabular}

Mortality.-There was no significant difference in overall mortality between the hospitals, Groby Road Hospital 24.5\% (25/102), Leicester General Hospital 25.8\% (38/147), and Leicester Royal Infirmary $24.7 \%$ (40/162).

Mortality by Severity of Infarction (Tables I and II).Neither by the coronary prognostic index nor by clinical grading were there any clear differences between monitored (Groby Road Hospital) and non-monitored patients.

Arrhythmias (Tables III and IV). - At Groby Road Hospital the number of patients observed to have an arrhythmia on admission or at any time of the hospital stay was higher, and their mortality was lower, than at the other two hospitals.

TABLE III.-Observation of an Arrhythmia on Admission. Percentage Frequency and Mortality

\begin{tabular}{|c|c|c|c|c|c|c|c|}
\hline \multirow{2}{*}{ Hospital } & \multirow{2}{*}{ Total } & \multicolumn{3}{|c|}{ No Arrhythmia } & \multicolumn{3}{|c|}{ Arrhythmia } \\
\hline & & No. & $\%$ & $\% \dagger$ & No. & $\%$ & $\% t$ \\
\hline $\begin{array}{ll}\text { G.R.H. } & \cdots \\
\text { L.G.H. } & \cdots \\
\text { L.R.I. } & \cdots\end{array}$ & $\begin{array}{l}102 \\
147 \\
162\end{array}$ & $\begin{array}{l}48 \\
98 \\
99\end{array}$ & $\begin{array}{l}47 \\
67 \\
61\end{array}$ & $\begin{array}{l}21 \\
18 \\
17\end{array}$ & $\begin{array}{l}54 \\
49 \\
63\end{array}$ & $\begin{array}{l}53 \\
33 \\
39\end{array}$ & $\begin{array}{l}28 \\
41 \\
36\end{array}$ \\
\hline
\end{tabular}

TABLE IV.-Observation of an Arrhythmia Throughout Whole Admission. Percentage Frequency and Mortality

\begin{tabular}{|c|c|c|c|c|c|c|c|}
\hline \multirow{2}{*}{ Hospital } & \multirow{2}{*}{ Total } & \multicolumn{3}{|c|}{ No Arrhythmia } & \multicolumn{3}{|c|}{ Arrhythmia } \\
\hline & & No. & $\%$ & $\% \dagger$ & No. & $\%$ & $\% \dagger$ \\
\hline $\begin{array}{ll}\text { G.R.H. } & \cdots \\
\text { L.G.H. } & \cdots \\
\text { L.R.I. } & \quad\end{array}$ & $\begin{array}{l}102 \\
147 \\
162\end{array}$ & $\begin{array}{l}39 \\
85 \\
90\end{array}$ & $\begin{array}{l}38 \\
58 \\
56\end{array}$ & $\begin{array}{l}18 \\
20 \\
13\end{array}$ & $\begin{array}{l}63 \\
62 \\
72\end{array}$ & $\begin{array}{l}62 \\
42 \\
44\end{array}$ & $\begin{array}{l}29 \\
34 \\
39\end{array}$ \\
\hline
\end{tabular}

TABle V.-Death in First 48 Hours After Admission

\begin{tabular}{|c|c|c|c|c|c|}
\hline \multirow{2}{*}{\multicolumn{3}{|c|}{ Hospital }} & \multicolumn{3}{|c|}{ First 48 Hours } \\
\hline & & & Deaths & $\begin{array}{l}\% \text { Total } \\
\text { Deaths }\end{array}$ & $\begin{array}{l}\% \text { Death of } \\
\text { All Patients }\end{array}$ \\
\hline $\begin{array}{l}\text { G.R.H. } \\
\text { L.G.H. } \\
\text { L.R.I. }\end{array}$ & & $\begin{array}{l}. \\
\cdots \\
.\end{array}$ & $\begin{array}{l}12 \\
19 \\
18\end{array}$ & $\begin{array}{l}48(12 / 25) \\
50(19 / 38) \\
45(18 / 40)\end{array}$ & $\begin{array}{l}12(12 / 102) \\
13(19 / 147) \\
11(18 / 162)\end{array}$ \\
\hline
\end{tabular}


Death in First 48 Hours After Admission (Table V).-No improvement resulted in the mortality at Groby Road Hospital during this period of routine cardiac monitoring.

Attempt at Cardiac Resuscitation on Patients Dying in First 48 Hours After Admission (Table VI).-During this period of routine cardiac monitoring at Groby Road Hospital it was not at this hospital but at the Leicester General Hospital where an attempt at cardiac resuscitation on patients dying was most frequently made.

TABLE VI.-Cardiac Resuscitation Attempt on Patients Dying Within 48

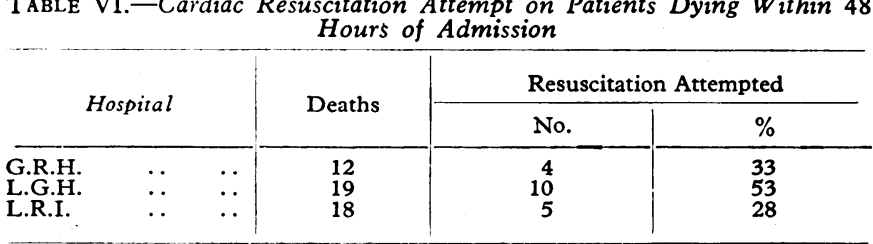

\section{Discussion}

This study shows that routine cardiac monitoring without the full facilities of a coronary care unit, where patients are under continuous nursing and/or medical observation, did not lower the overall mortality from acute myocardial infarction. The mortality of $25 \%$ for both non-monitored and monitored patients is about 7 to $10 \%$ higher than the reported mortality of most coronary care units.

The frequency of observation of one or more arrhythmias on admission or at any time of the hospital stay was highest at Groby Road Hospital and the mortality for these patients was lowest at this hospital. Groby Road Hospital is a regional cardiac unit, and, though not possessing a coronary care unit, all patients were routinely monitored for the first 48 hours or longer if necessary. Arrhythmias were carefully searched for by medical and senior nursing staff and then actively treated. It was this attitude aided by the monitors, rather than the presence of monitors per se, that is thought to have been responsible for the increased frequency of observation and lower mortality from arrhythmias at Groby Road Hospital. The finding that more patients on admission-that is, before monitoring-were observed to have an arrhythmia at Groby Road Hospital than at the other two hospitals supports this view.

\section{Alarm Systems}

The mortality during the first 48 hours and the frequency of an attempt at cardiac resuscitation of patients dying during this period of monitoring were not improved at Groby Road Hospital. Cardiac arrest at this hospital was diagnosed by the patient being seen to collapse rather than by the sounding of monitor alarms. Alarm systems on monitors are frequently unreliable, often sounding false alarms when the patient moves. The incidence of these false alarms may be decreased by the careful placement of adhesive chest electrodes, but it is difficult to eliminate them completely. Likewise, it is dangerous to rely on the monitor alarm to consistently announce cardiac arrest, and it is no substitute for observation of the patient. For these reasons, in at least two coronary care units alarm systems are no longer used (Pentecost and Mayne, 1968 ; Thomas et al., 1968).

In the modern management of acute myocardial infarction great emphasis is laid on the early detection and treatment of arrhythmias to prevent the occurrence of cardiac arrest (Lown et al., 1967). This implies that both patient and monitor must be regularly observed by trained personnel, and without a coronary care unit this is difficult to achieve. This difficulty is even greater at night, where there are fewer nurses, who are often of a more junior grade. The results from coronary care units in general hospitals (Pentecost and Mayne, 1968 ; Smith, 1968) suggest that, though a doctor need not be present continuously, it is essential that there be a sufficient number of adequately trained nurses.

At some hospitals, following the recent introduction of cardiac monitoring, the nurse is neither particularly encouraged to observe the monitor nor has she been taught to recognize the normal and abnormal E.C.G. rhythm traces. Often the only abnormal trace that a nurse is able to recognize is that due to a displaced electrode. Owing to the pressure of work, junior medical staff are able to observe monitors only infrequently. Consequently major arrhythmias may pass unnoticed, despite their clear demonstration on the monitor.

This discussion is not to decry the use of cardiac monitoring in a general ward. Monitors stimulate interest in the detection of arrhythmias and are useful in their treatment. However, the limitations of their value must be recognized. This study suggests that, in the absence of almost continuous observation of patient and monitor by trained personnel, the routine use of cardiac monitors will not lower mortality from acute myocardial infarction.

We acknowledge with pleasure the collaboration of the consultant physicians at the Leicester General Hospital and the Leicester Royal Infirmary, who allowed us to study the case notes of patients admitted under their care. We thank Professor J. P. Shillingford, who kindly read the paper and offered constructive criticism. We are grateful to Dr. Margaret White for help with the analysis of the case notes.

Requests for reprints should be addressed to: Dr. P. J. B. Hubner, Department of Medicine, Hammersmith Hospital, London W.12.

\section{REFERENCES}

Fluck, D. C., et al. (1967). Brit. Heart F., 29, 179.

Lawrie, D. M., et al. (1967). Lancet, 2, 109.

Lown, B.; Fakhro, A. M., Hood, W. B., and Thorn, G. W. (1967). J. Amer. med. Ass., 199, 188. Peel, A. A. F., Semple, T.; Wang, I., Lancaster, W. M., and Dall,

Pentecost, B. L., and Mayne, N. M. C. (1968). Brit. med. F., 1, 830.

Rescieaux, N., et al. (1967). Lancet, 1, 1285.

Smith, W. G. (1968). Lancet, 2, 397.

Thomas, M., Jewitt, D. E., and Shillingford, J. P. (1968). Brit. med. Y., 1, 787. 